Onur Çavuşoğlu

Hakan Gürün

https://doi.org/10.21278/TOF.41305

ISSN 1333-1124

eISSN 1849-1391

\title{
STATISTICAL EVALUATION OF THE INFLUENCE OF TEMPERATURE AND SURFACE ROUGHNESS ON ALUMINIUM SHEET METAL FORMING
}

\begin{abstract}
Summary
The influences of temperature and surface roughness on the forming of the AA3003H111 aluminium alloy sheet material have been investigated by using the finite element method. For this purpose, material cards have been firstly created based on the sheet material behaviour at different deformation temperatures. As a result of the forming analyses performed at different temperature values and surface roughness values, it has been determined that the increase in the surface roughness reduces the amount of thinning while it increases the amount of forming force and the springback. It has also been determined that there is a slight increase in the amount of thinning, while the temperature rise reduces the amount of forming force and the springback. In addition, the influence levels of temperature and surface roughness have been determined by statistical analyses.
\end{abstract}

Key words: $\quad$ temperature, surface roughness, AA3003, ANOVA

\section{Introduction}

Aluminium alloyed sheet materials are preferred for energy saving by reducing vehicle weight, due to their high strength-to-weight ratio and corrosion resistance [1-2]. Sheet metal forming processes are affected by many different parameters such as surface quality (lubrication conditions), temperature, blank holder pressure and forming speed [3-4]. Aluminium alloys exhibit the properties of high ductility and formability at temperatures below the recrystallization temperature although they have low formability at room temperature [1-2]. Determination of sheet metal forming process parameters saves time and costs. For this purpose, the effects of the process parameters on the forming process can be determined by performing analyses using the finite element method [4-7]. Temperature affects mechanical properties of the material. Therefore, it also affects the yield surface which occurs depending on the plastic deformation in the sheet during forming. Several studies have been conducted related to this subject. Abedrabbo studied with his colleagues the deformation behaviour and formability of the AA3003-H111 sheet material depending on the temperature [8-9]. Toros et al. investigated the effects of different material models on the finite element 
analysis [10]. Kurukuru et al. studied the material models of the AA6016-T4 aluminium alloy under the effect of temperature in forming simulations [11]. Kotkunde et al. compared their model with experimental results by creating different material models of the warm forming of the Ti-6Al-4V alloy [12]. Naka et al. investigasted the effect of temperature on the yield surface of aluminium alloys [13]. Laurent et al. evaluated the amount of the forming force, distribution of sheet thickness and springback by analysing experimentally and numerically the warm deep drawing process of Al-Mg alloys [14]. Huang and Cheng analysed the effects of lubricant and surface roughness in the drawing process [15]. Warm temperatures in the forming process ensure better formability of aluminium alloy sheets. After evaluation of the studies found in the literature, it can be concluded that temperature is an important parameter in the forming of aluminium alloys and that influences of surface roughness have not been adequately analysed. In this study, influences of temperature and surface roughness on the forming of the AA3003-H11 sheet material have been analysed and the influence level of temperature and surface roughness have been determined.

\section{Material}

The widely used AA3003-H111 aluminum alloy sheet material has been selected for the analysis of the forming process. The chemical composition of this material is given in Table 1 .

Table 1 Chemical composition of AA3003-H111 (weight percent) [8]

\begin{tabular}{ccccccccccc}
\hline Material & $\mathrm{Mg}$ & $\mathrm{Mn}$ & $\mathrm{Si}$ & $\mathrm{Fe}$ & $\mathrm{Ti}$ & $\mathrm{Zn}$ & $\mathrm{Cu}$ & $\mathrm{Ni}$ & $\mathrm{Cr}$ & $\mathrm{Al}$ \\
\hline $\mathrm{AA3} 3003-\mathrm{H} 111$ & 0.02 & 1.10 & 0.21 & 0.50 & 0.02 & 0.01 & 0.07 & 0.005 & 0.005 & $\mathrm{Bal}$ \\
\hline
\end{tabular}

\section{Forming Analyses}

The influences of temperature and surface roughness on the formability of sheet materials have been investigated by using the finite element method. The forming analyses for the AA3003-H111 aluminium alloy were performed with a hemispherical punch at $25^{\circ} \mathrm{C}, 93$ ${ }^{\circ} \mathrm{C}, 177^{\circ} \mathrm{C}, 260{ }^{\circ} \mathrm{C}$ and $0.01 \mu, 0.2 \mu, 0.4 \mu, 0.6 \mu$ punch surface roughness values. For this purpose, the mechanical properties of the AA3003-H111 aluminium alloy sheet material at different temperatures have been obtained from study of Abedrabbo et al. [8]. By using the Hill yield criterion, material cards have been created in order to perform the finite element analysis at a specified temperature and transferred to the analysis software. The mechanical properties of the AA3003-H111 aluminium alloy sheet material used in the finite element analysis are presented in Table 2.

Table 2 Mechanical properties of AA3003-H111 [8]

\begin{tabular}{ccccccc}
\hline Temperature $\left({ }^{\circ} \mathrm{C}\right)$ & $\varepsilon_{0}$ & n value & $\mathrm{K}$ value & $\mathrm{r}_{0}$ & $\mathrm{r}_{45}$ & $\mathrm{r}_{90}$ \\
\hline 25 & $8.30 \mathrm{E}-04$ & 0.215 & 199.82 & 0.827 & 1.126 & 0.773 \\
93 & $6.64 \mathrm{E}-04$ & 0.179 & 168.41 & 1.247 & 1.690 & 0.879 \\
177 & $6.20 \mathrm{E}-04$ & 0.157 & 119.65 & 1.413 & 1.975 & 1.007 \\
260 & $5.05 \mathrm{E}-04$ & 0.116 & 77.32 & 2.035 & 2.485 & 1.328 \\
\hline
\end{tabular}

Sheet metal forming analysis software calculate the deformation in the sheet material depending on the yield function, yield stress and the anisotropy value. To this end, researchers worked on different models [8-12]. The preferred criterion is the Hill-48 model yield criterion, which is often used in forming analyses. The Hill-48 yield function is explained in Eq. (1-3) [10]. 


$$
2 f\left(\sigma_{i j}\right)=F\left(\sigma_{y}-\sigma_{z}\right)^{2}-G\left(\sigma_{z}-\sigma_{x}\right)-H\left(\sigma_{x}-\sigma_{y}\right)+2 L \tau_{y z}^{2}+2 M \tau_{z x}^{2}+2 N \tau_{x y}^{2}=1
$$

where $F, G, H, L, M$ and $N$ are the material constants and $\mathrm{x}, \mathrm{y}$ and $\mathrm{z}$ are the mutual orthogonal axes of orthotropy. The Hill-48 quadratic yield function can also be written as:

$2 f\left(\sigma_{i j}\right)=(G+H) \sigma_{x}^{2}-2 H \sigma_{x} \sigma_{y}+(H+F) \sigma_{y}^{2}+2 N \tau_{x y}^{2}=1$

In Eq. (2), the $F, G, H$ and $N$ parameters can also be written in terms of the anisotropy parameters $r_{0}, r_{45}, r_{90}$.

$$
\begin{array}{ll}
F=\frac{r_{0}}{r_{90}\left(1+r_{90}\right)} & G=\frac{1}{\left(1+r_{0}\right)} \\
H=\frac{r_{0}}{\left(1+r_{0}\right)} & N=\frac{\left(r_{0}+r_{90}\right)\left(1+2 r_{45}\right)}{2 r_{90}\left(1+r_{0}\right)}
\end{array}
$$

The model parameters are given in Table 3. The forming process was applied by stretching the sheet with a hemispherical punch to determine the formability behavior of the sheet material. The tool model used in the forming analyses is shown in Figure 1. As a result of the forming analyses, the influences of the temperature and the friction coefficient on the forming force and the amount of thinning occurring in the sheet were determined.

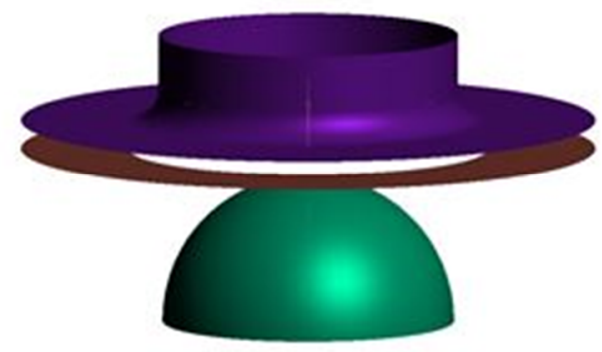

Fig. 1. Tool model

Table 3 Model parameters used in the formability simulation

\begin{tabular}{ccc}
\hline Mesh Refinement & $\begin{array}{c}\text { Initial Element Size } \\
\text { Radius Penetration }\end{array}$ & $\begin{array}{c}3 \mathrm{~mm} \\
0.1 \mathrm{~mm} \\
\text { Max Element Angle }\end{array}$ \\
$10^{\circ}$ \\
\hline Element Type & Elastic Plastic Shell \\
\hline Material Thickness & $1 \mathrm{~mm}$ \\
\hline
\end{tabular}

\section{Results and Discussion}

\subsection{Forming Force}

A certain amount of force is required so as to ensure sheet metal materials to change form through plastic deformation. In this study, the influences of the temperature and the punch surface roughness on the forming force were determined. It is known that the forming force decreases after the temperature increases [11,14]. The analysis of the relationship presented in Figure 2 among the forming force, the surface roughness and the temperature has shown that the forming force is substantially reduced as the temperature increases. The reason is that plastic deformation is carried out more easily due to the decrease in yield stress along 
with the increase in temperature. When the influence of surface roughness on the forming force was evaluated, it was determined that the increase in surface roughness increases the forming force at all temperatures. The increase in surface roughness makes the yielding of the sheet metal harder. Because of that a greater amount of force is required for the forming process to be carried out. It is also found in the studies from the literature that the increase in the surface quality leads to some increase in the forming force [15]. The lowest forming force was obtained at $260{ }^{\circ} \mathrm{C}$ at all surface roughness values used in the analyses. While the highest forming force of $22442 \mathrm{~N}$ was obtained at $25^{\circ} \mathrm{C}$ and the surface roughness value was $0.6 \mu$, the lowest forming force of $10055 \mathrm{~N}$ was obtained at $260^{\circ} \mathrm{C}$ and the surface roughness value was $0.1 \mu$.
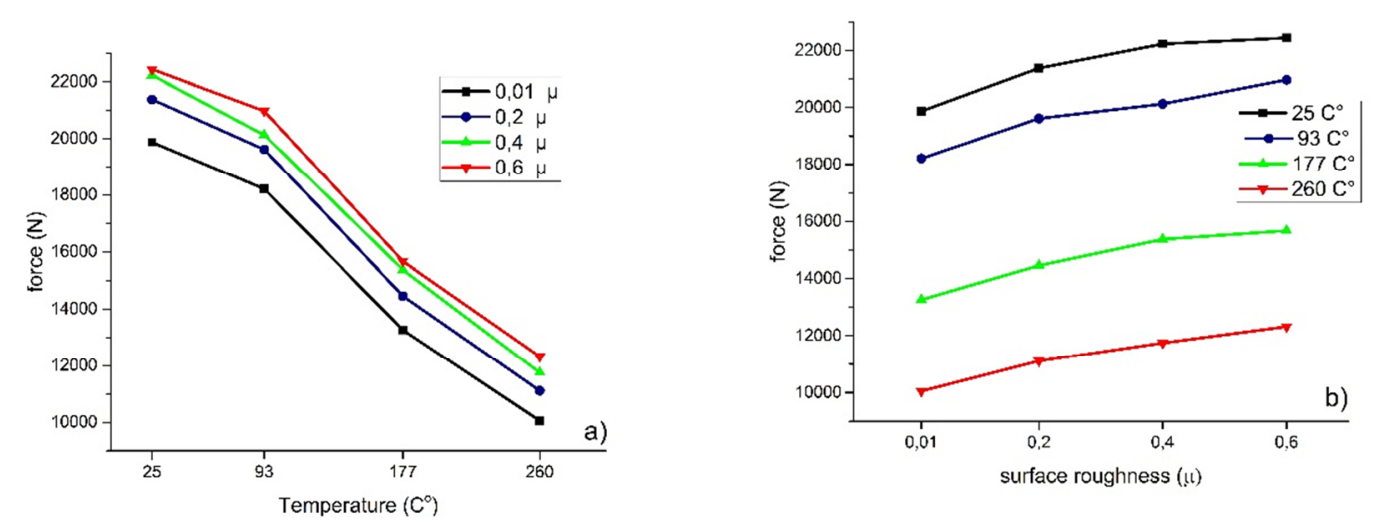

Fig. 2 Temperature-force (a) and surface roughness-force (b) relationships

\subsection{Thinning}

Thinning in the sheet thickness occurs subsequent to the forming process depending on the deformation in the forming processes of sheet metal materials. The relationship between thinning and temperature and thinning and surface roughness is given in Figure 3. It can be seen that the amount of thinning decreases as the surface roughness increases, while the amount of thinning shows a tendency towards an increase as the deformation temperature increases. This result is in accordance with the study of Laurent et al. [14]. While the highest amount of thinning is determined to be $34.4 \%$ at $260^{\circ} \mathrm{C}$ and the surface roughness value is $0.01 \mu$, the lowest amount of thinning is determined to be $31.4 \%$ at $25^{\circ} \mathrm{C}$ and the surface roughness value is $0.06 \mu$.
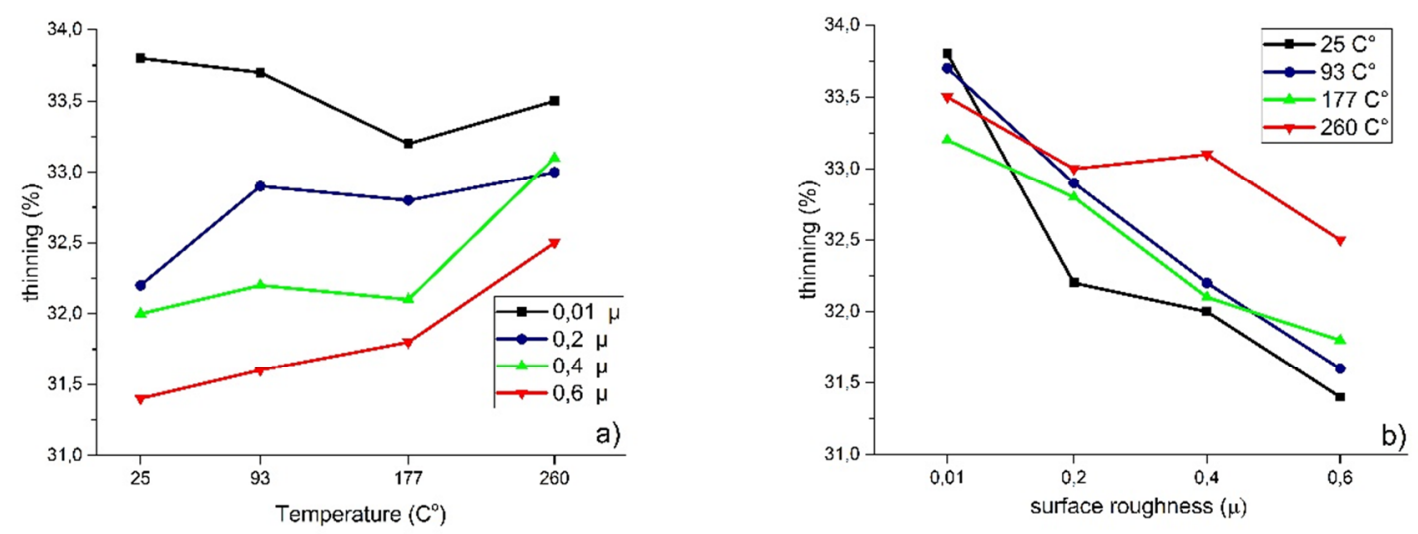

Fig. 3 Temperature-thinning (a) and surface roughness-thinning (b) relationship 


\subsection{Springback}

In the sheet metal forming process, the product geometry must be within the dimensional tolerances. However, dimensional errors due to the springback occurring following the plastic deformation are known to be among the most important problems encountered in the sheet metal forming process [4]. The influence of the surface roughness on the springback in the forming process is presented in Figure 4. A slight increase in the amount of springback occurring in the sheet material was determined as the surface roughness increases from $0.01 \mu$ to $0.4 \mu$. However, a significant change was not observed in other surface roughness values. It can be seen that the increase in the temperature value reduces substantially the amount of springback. The decrease in yield strength and strain hardening along with the increase in temperature [11] leads to the reduction in the amount of springback occurring after the forming process [14]. While the highest amount of springback is measured at the temperature of $25^{\circ} \mathrm{C}$ and the surface roughness value of 0.4 and $0.6 \mu$, the lowest amount of springback is measured at the temperature of $260^{\circ} \mathrm{C}$ and the surface roughness value of $0.01 \mu$. Besides, the lowest amount of springback was obtained at the temperature of $260{ }^{\circ} \mathrm{C}$ at all surface roughness values.
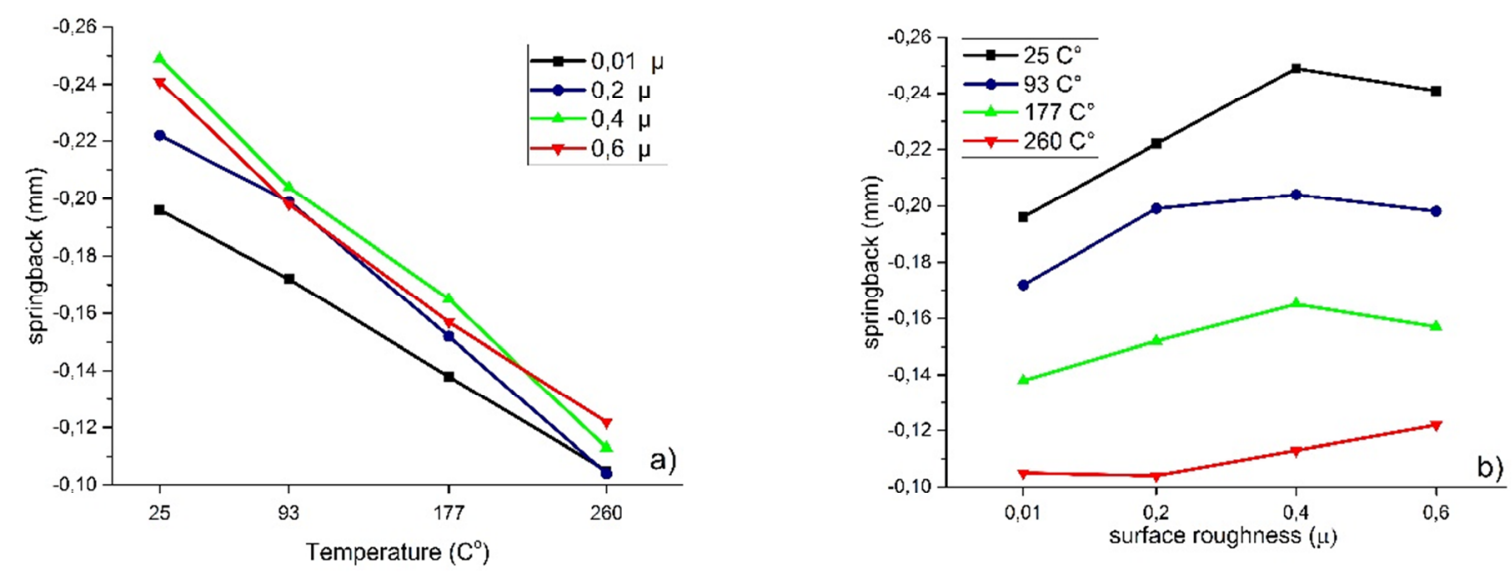

Fig. 4 Temperature-springback (a) and surface roughness-springback (b) relationships

\section{Statistical Evaluation}

The analysis of variance (ANOVA) and full factorial analyses were performed in order to determine the influence level of the investigated parameters in the scope of the study. The factors are given in Table 4.

Table 4 Factor levels

\begin{tabular}{ccccc}
\hline Factor & \multicolumn{4}{c}{ Levels } \\
\hline Temperature $\left(\mathrm{C}^{\circ}\right)$ & 25 & 93 & 177 & 260 \\
\hline Surface roughness $(\mu)$ & 0.01 & 0.2 & 0.4 & 0.6 \\
\hline
\end{tabular}

The temperature and surface roughness were found to be significant factors $(\mathrm{P}<0.05)$ when the ANOVA and full factorial analysis results for temperature, forming force and surface roughness were analysed (Table 5). It has been found that the influence of temperature is $94.7 \%$, of surface roughness $5.2 \%$ and of temperature together with surface roughness $0.1 \%$ 
regarding the forming force. Accordingly, it can be said that temperature is the main factor affecting the forming force.

Table 5 ANOVA and full factorial analysis results for temperature, forming force and surface roughness

\begin{tabular}{ccccccc}
\hline Source & DF & Seq SS & Adj SS & Adj MS & P & C \\
\hline Temperature & 3 & 260454637 & 260454637 & 86818212 & 0.01 & $94.7 \%$ \\
Surface roughness & 3 & 14257402 & 14257402 & 4752467 & 0.01 & $5.2 \%$ \\
Temperature*Surface roughness & 9 & 224016 & 224016 & 24891 & - & $0.1 \%$ \\
Error & 0 & - & - & - & - & - \\
Toplam & 15 & 263564439 & R-Sq $=99.92 \%$ & & \\
\hline
\end{tabular}

Temperature and surface roughness are significant factors $(\mathrm{P}<0.05)$ regarding the amount of thinning according to ANOVA. Full factorial analysis results for temperature, forming force and surface roughness are given in Table 6.

It is concluded that the influence on thinning of temperature is $31.2 \%$, of surface roughness $56 \%$, and of temperature together with surface roughness $12.8 \%$. Thus, surface roughness is observed to be the main factor affecting thinning.

Table 6 ANOVA and full factorial analysis results for temperature, forming force and thinning

\begin{tabular}{ccccccc}
\hline Source & DF & Seq SS & Adj SS & Adj MS & P & C \\
\hline Temperature & 3 & 3.46250 & 3.46250 & 1.15417 & 0.009 & $31.2 \%$ \\
Surface roughness & 3 & 6.19250 & 6.19250 & 2.06417 & 0.001 & $56 \%$ \\
Temperature*Surface roughness & 9 & 1.42250 & 1.42250 & 0.15806 & - & $12.8 \%$ \\
Error & 0 & - & - & - & & - \\
Total & 15 & 11.07750 & & R-Sq $=87.16 \%$ & - & \\
\hline
\end{tabular}

Temperature and surface roughness are observed to be significant factors $(\mathrm{P}<0.05)$ affecting the springback when ANOVA and full factorial analysis results carried out for the springback are analysed (Table 7). Temperature is determined to be the main factor affecting the springback by the influence of $91.3 \%$. In addition to this case, it can be said that surface roughness does not have significant influence on the springback with its influence of only $6.6 \%$.

Table 7 ANOVA and full factorial analysis results for the temperature, forming force and springback

\begin{tabular}{ccccccc}
\hline Source & DF & Seq SS & Adj SS & Adj MS & P & C \\
\hline Temperature & 3 & 0.0302202 & 0.0302202 & 0.0100734 & 0.004 & $91.3 \%$ \\
Surface roughness & 3 & 0.0021857 & 0.0021857 & 0.0007286 & 0.001 & $6.6 \%$ \\
Temperature* Surface roughness & 9 & 0.0006991 & 0.0006991 & 0.0000777 & - & $2.1 \%$ \\
Error & 0 & - & - & - & & - \\
Total & 15 & 0.0331049 & & R-Sq $=97.89 \%$ & - & \\
\hline
\end{tabular}




\section{Conclusions}

The results obtained in this study are summarized as follows:

- As a result of the forming analyses it has been found that the required forming force has largely been reduced because the increase in temperature has reduced the mechanical properties of the material. Surface roughness has also increased the forming force because it made the yielding of sheet hard.

- A slight increase in the amount of thinning occurs as the deformation temperature increases and a reduction in the amount of thinning occurs as surface roughness increases. However, the change takes place over only a very small range.

- The amount of springback occurring in the sheet material following the forming process is significantly reduced as temperature increases and the amount of springback is not significantly affected by the increase in surface roughness.

- The analysis of the influence of the forming parameters showed that temperature highly affects the forming force (influence of 94.7\%) and the springback (influence of $91.3 \%$ ) and that surface roughness has an influence only on the amount of thinning (influence of $56 \%$ ).

\section{REFERENCES}

[1] Toros, S., Ozturk, F., Kacar, I., Review of warm forming of aluminum-magnesium alloys. Journal of Materials Processing Technology, 2008, 207, pp. 1-12. https://doi.org/10.1016/j.jmatprotec.2008.03.057

[2] Abovyana, T., Kridli, G.T., Friedmanb, P.A., Ayoubc, G., Formability prediction of aluminum sheet alloys under isothermal forming conditions, Journal of Manufacturing Processes, 2015, 20 pp. 406-413. https://doi.org/10.1016/j.jmapro.2014.08.003

[3] Rahu, S., Ganesan, G., Karthikeyan, R., Influence of variables in deep drawing of AA 6061 sheet", Trans. Nonferrous Met.Soc. China, 2010, 20, pp. 1856-1862. https://doi.org/10.1016/S1003-6326(09)60386-1

[4] Cavusoglu, O., Gurun, H., Investigation of the effects of deformation speed on the mechanical properties and deep drawing process of DP600 and DP780 sheet metal", Journal of The Faculty of Engineering and Architecture of Gazi University, 2014, 29 (4), pp. 777-784.

[5] Colgan, M., Monaghan, J., Deep drawing process: analysis and experiment, Journal of Materials Processing Technology, 2003, 132, pp. 35-41. https://doi.org/10.1016/S0924-0136(02)00253-4

[6] Yılız, H., Kirlı. O. Non-linear finite element modeling of deep drawiig process, journal of engineering sciences, 2004, 10 (3), pp. 317-326, (In Turkish).

[7] Volk, M., Nardin, B., Dolšak, B., Application of Numerical Simulations in the Deep-Drawing Process and the Holding System with Segments' Inserts, Strojniški vestnik - Journal of Mechanical Engineering, 2011,57 (9), pp. 697-703.

[8] Abedrabbo, N., Pourboghrat, F., Carsley, J., Forming of aluminum alloys at elevated temperatures - Part 1: Material characterization, International Journal of Plasticity, 2006, 22, pp. 314-341. https://doi.org/10.1016/j.ijplas.2005.03.005

[9] Abedrabbo, N., Pourboghrat, F., Carsley, J., Forming of aluminum alloys at elevated temperatures - Part 2: Numerical modeling and experimental verification, International Journal of Plasticity, 2006, 22, pp. 342-373. https://doi.org/10.1016/j.ijplas.2005.03.006

[10] Toros, S., Polat, A., Ozturk, F., Formability and spring back characterization of TRIP800 advanced high strength steel, Materials and Design, 2012, 41, pp. 298-305. https://doi.org/10.1016/j.matdes.2012.05.006

[11] Kurukuri, S., Miroux, A., Ghosh, M., Boogaard, A.H., Effect of temperature on anisotropy in forming simulation of aluminum alloys, Int J Mater Form, 2009, 2 (1), pp. 387-390.

https://doi.org/10.1007/s12289-009-0462-4 
[12] Kotkunde, N., Deole, A.D., Gupta, A.K., Singh, S.K., Experimental and numerical investigation of anisotropic yield criteria for warm deep drawing of Ti-6Al-4V alloy, Materials and Design, 2014, 63, pp. 336-344. https://doi.org/10.1016/j.matdes.2014.06.017

[13] Naka, T., Nakayama, Y., Uemori, T., Hino, R., Yoshida., Effects of temperature on yield locus for 5083 aluminum alloy sheet, Journal of Materials Processing Technology, 2003, 140, pp. 494-499. https://doi.org/10.1016/S0924-0136(03)00780-5

[14] Laurent, H., Coër, J., Manach, P.Y., Oliveira, M.C., Menezes, L.F., Experimental and numerical studies on the warm deep drawing of an Al-Mg alloy, International Journal of Mechanical Sciences, 2015, 93, pp. 59-72. https://doi.org/10.1016/j.ijmecsci.2015.01.009

[15] Huang, Y.M., Cheng, J.W., Influence of lubricant on limitation of formability of cylindrical cup-drawing, Journal of Materials Processing Technology, 1997, 63, pp. 77-82.

https://doi.org/10.1016/S0924-0136(96)02603-9

$\begin{array}{lll}\text { Submitted: } & \text { 17.6.2016 } & \text { Onur Çavuşoğlu } \\ \text { Accepted: } & 30.9 .2016 & \text { Hakan Gürün } \\ & \text { Gazi University, } \\ & \text { Faculty of Technology, } \\ & \text { Department of Manufacturing } \\ & \text { Engineering, Ankara - Turkey } \\ & \text { onurcavusoglu@gazi.edu.tr, } \\ & \text { hgurun@gazi.edu.tr }\end{array}$

